\title{
Solar Elevation Angle and Solar Culmination Determination using Celestial Observation; A Case Study Of Hadejia Jigawa State, Nigeria
}

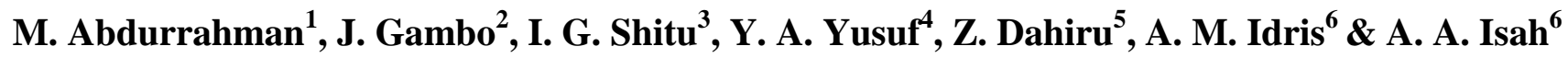 \\ ${ }^{1}$ Department of physics, faculty of Natural science, Federal University Dutse, Jigawa State, Nigeria \\ ${ }^{2}$ School of General Studies, Binyaminu Usman Polytechnic, Hadejia P.M.B 013 Jigawa State, Nigeria \\ ${ }^{3}$ Department of physics, faculty of Natural science, Sule Lamido University Jigawa State, Nigeria \\ ${ }^{4}$ Dept. of Environmental Management, Faculty of Earth and Environmental Science, Bayero University, Kano Nigeria \\ ${ }^{5}$ Department of physics, School of Science, Jigawa State College of Education Gumel, Nigeria \\ ${ }^{6}$ School of Science, Binyaminu Usman Polytechnic, Hadejia P.M.B 013 Jigawa State, Nigeria
}

\begin{abstract}
The world typically depends on renewable resources because of its zero-emission. The most important and available resource is solar energy, which is found almost accessible in each and every location of the world. Solar energy is among the abundant renewable resources and is the alternative most fundamental sources of energy. It is mandatory to determine the solar azimuth angle, solar altitude angle together with the understanding of solar culmination relatively to the time and collection device location. This work was conducted in Hadejia Jigawa state of northern Nigeria. The main objective of this study was to identify the maximum and minimum solar elevation angle (SEA), solar azimuth angle (SAA), solar culmination (SC) and questions of time (EOT) of the study area. Keisan online calculator was used as a method to track the sun path/position and corresponding data such as solar altitude and azimuth angle, culmination and equations of time. Keisan calculator can be used trace sun specific location for any spatial location of the earth. The results shows $178^{\circ}$ SAA, maximum SC 12:34:02, maximum SEA $85^{\circ}$ and maximum EOT 16.323 respectively. The findings of this paper will help decision-makers and engineers understand the peak sun angle, sun path/position and also use for solar harvesting technology in the study, especially during solar panels installation.
\end{abstract}

Key Words: Solar observations, Solar energy, Renewable resource, Equations of time.

\subsection{INTRODUCTION}

Mankind has regarded the Sun as the abundant source of renewable energy with zero emission (Panwar and Kaur, 2014; Kumar 2010). Solar energy coming down to the surface of the earth's per year is approximately ten thousand times the worldwide energy consumption per year. Using solar energy has therefore, has drawn the attention of many scientific reasearchers, technologists, economists, sociologists and politicians. Much efforts haves therefore been directed towards developing new and better solar energy conversion devices. For decades, man has been trying to make use of solar enegy as an important source of energy. The best energy utilization that comes from the sun will be successefully achieved when the sun path and position can be determined. In solar energy applications development, sun-tracking plays an significant role, particularly for generating electrical or thermal energy from directly solar energy. The Keisan calculator was desinged inorder to calculate a table of changes in the solar elavation and azimuth angles for a day (or a year) with some input such as latitude, longitude, date, time zone, daylight saving time in order to detect and track sun position for particular geographic location.

\subsection{METERIALS AND METHODS}

Firstly a specific location must be selected by finding its latitude, longitude followed by the distance above sea level using portable Gps receiver. Hadejia town in Jigawa State, Nigeria was selected as area of interst for this study with latitude 12,4481N, longitude $10,0436 \mathrm{E}$ and altitude of $337 \mathrm{~m}$. Secondly the remaining input includes; date, time zone, and daylight saving time are also inputted. A table of changes in the solar elevation, azimuth angles and solar culmination and equations of time would generated as part of results. 
A graph of solar elevation angle in degrees and equations of time in minute was plotted against months of a year. Figure 1: indicate the methodological workflow.

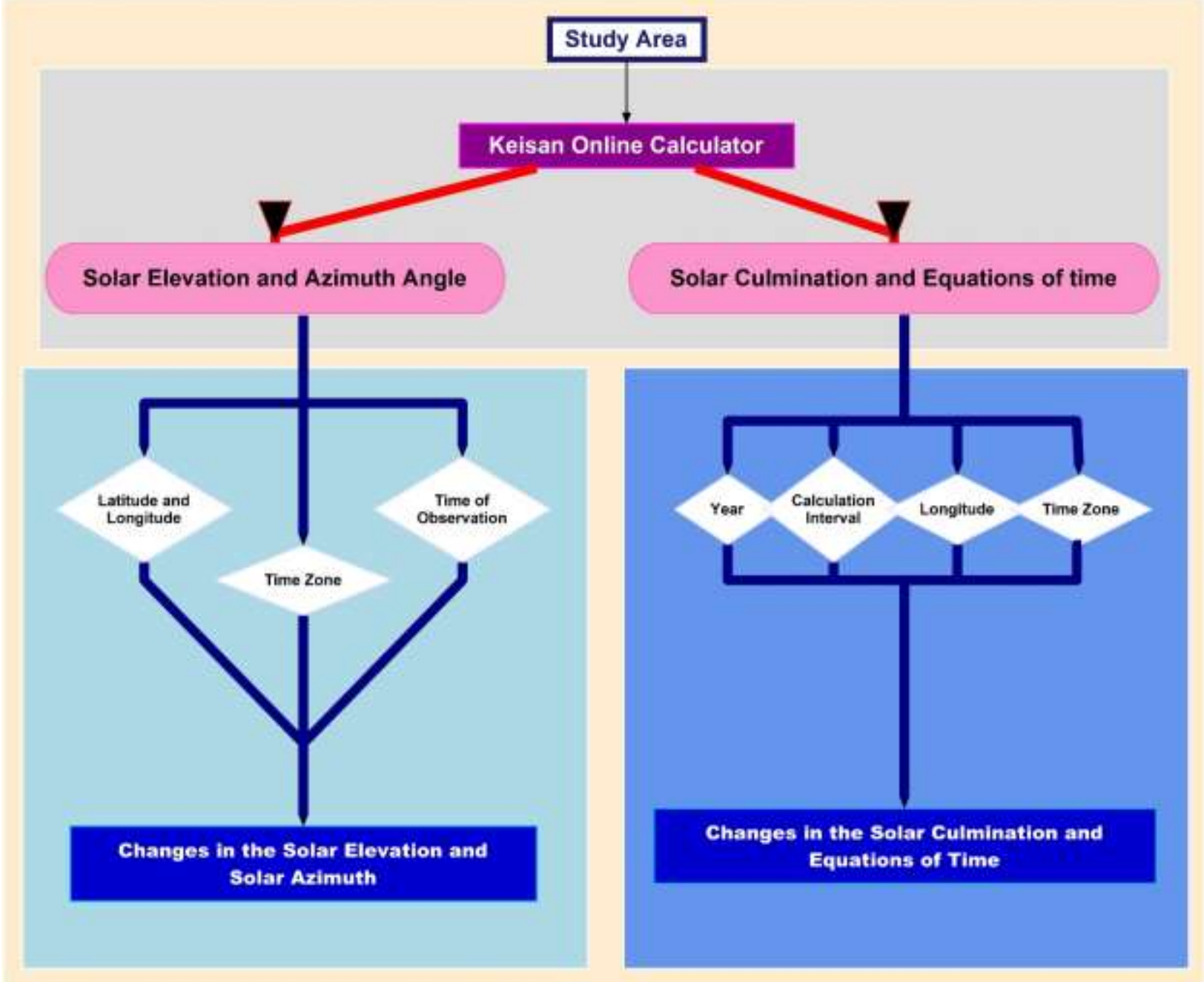

Figure 1: Method workflow.

\subsection{RESULTS AND DISCUSSION \\ 3.1 DISCUSSION}

\subsubsection{Culmination And Equations of Time}

When a star's hour circle is coincident with the observer's celestial meridian, it is said to culminate or transit (Pio, 1899). Solstices are two points which are far away from the celestial equator. Solstices are of two types; the far point above the celestial equator called the summer solstice and the far point below the celestial equator called the winter solstices. Furthermore, the ecliptic intersects the Earth's equator at two points.

\subsubsection{Equinox}

The appearance of the Sun exactly above the equator gives an occasion known as the Equinox. As the Earth continues in its revolution, each year the sun crosses the equator twice: once heading South which leads to our Summer, and once heading North as we move through Autumn leading us to our to Winter. September $23^{\text {rd }}$ is where Our Spring Equinox occurred while $22^{\text {nd }}$ March is where our Autumn Equinox is. The Sun rises precisely in the East, and sets precisely in the West on these two dates. The word "equinox" means "the same"; so on these two days the Sun is visible for the same distance of time as it is night (all around the Earth).

Equinoxes are divided into two types, namely the vernal equinox which is the location where the Sun traverse the equator from the southern half of the celestial sphere to northern half of the celestial sphere and the autumnal equinox where the Sun traverse the equator from the northern half to southern half of the celestial sphere. To help in figuring the equinoxes and solstices, we had made a model which explains these points to a certain level. For easiest way, we explain these four points with respect to the northern 
hemisphere. The vernal (or spring) equinox is where the axis on the Earth points perpendicular to the Sun. The Sun's rays directly hit the equator. This day is usually on 20 or 21 March. As the word "equinox" means "the same night", the nighttime and daytime are of the same distance everywhere on the universe, each last up to 12 hours. In western astronomy, the vernal equinox points the starting of spring. We can define the locations of the equinoxes and solstices by using the equatorial frame of reference.

For an ellipse the ratio of its distance from a unchanged point $(\mathrm{F})$ to the unchanged straight line is always a constant. This ratio is called as eccentricity. For Ellipse: eccentricity is constantly less than one $(<1)$.

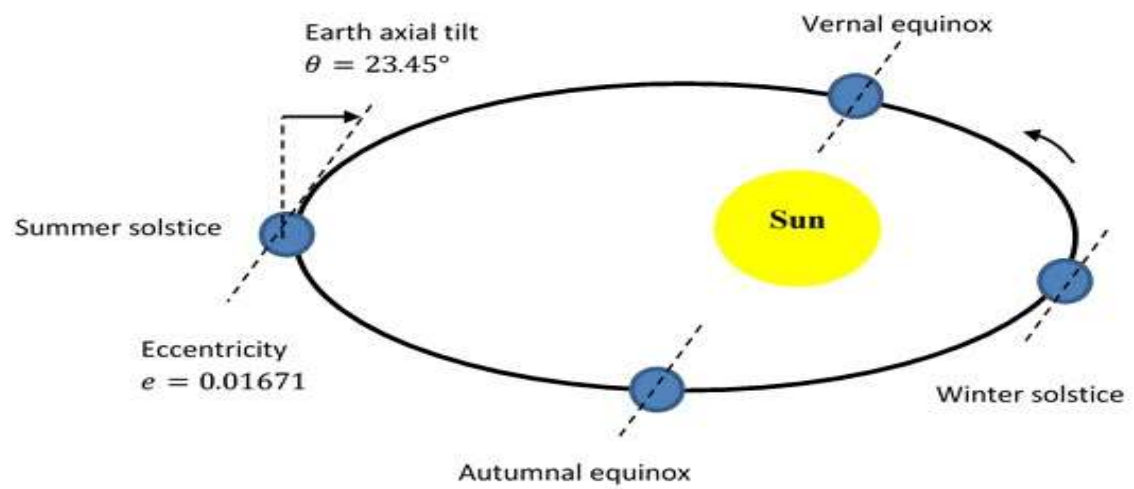

\subsubsection{Equation of Time}

Figure 2: The equinox's diagrams

The Equation of Time is the quantity by which true solar time differs from mean (clock) time [5]. It is the difference, over the course of a year, between time as read from a sundial and a clock, in an perfect situation, which would be at the centre of a time zone, in an area that are not in needed of daylight saving time. The sundial can be ahead (fast) by as much as 993s (around November 3) or fall behind by as much as $846 \mathrm{~s}$ (around February 12). It is because of the irregularity in the way of the Sun across the sky, due to a combination of the obliquity of the Earth's rotation axis and the eccentricity of its orbit. Apparently by general convention a negative value for the equation of time means that the sun-dial time is behind the clock (mean) time and a positive value means sun-dial time is ahead of clock time.

\subsubsection{Solar Year}

Solar year is the time for the earth to make on revolution around the sun measure between two vernal equinoxes.

\subsubsection{Earth-Sun Angles}

The sun's declination angle, $\mathrm{d}$, the hour angle, $\mathrm{h}$, and the latitude, $\mathrm{l}$, will be basically used to calculate the location of a point $\mathrm{P}$ on the surface of the earth's with respect to the solar radiation if are known at any instant. It is explained in Figure 3 [2].

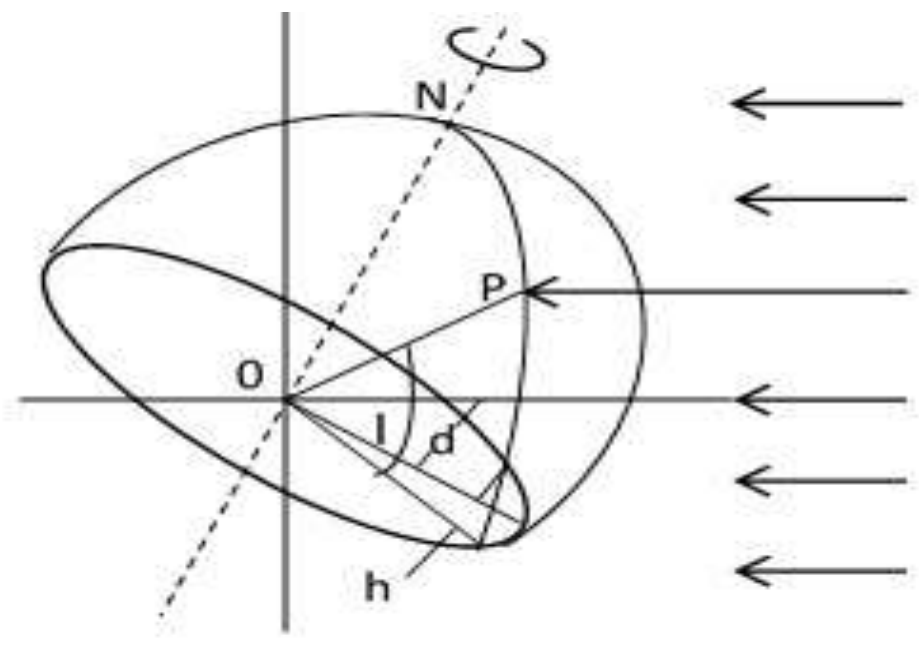

Figure 3: Latitude, hour angle and Sun's declination angles

\subsubsection{Latitude}


Latitude, 1, is an imaginary line usually found around the globe parallel to the equator. It is the angle between OP and the projection of OP on the equatorial plane [2]. The midpoint of the earth is represented by a capital letter O. North latitudes of the earth are reckoning positive while the south latitudes are reckoning negative.

\subsubsection{Hour Angle}

The hour angle, $\mathrm{h}$, is the angular distance along the celestial equator from the obserber's meridian to the hour circle of a given celestial body. The hour angle commute the local solar time (LST) into the number of degrees by which the sun moves within the sky. By definatio, the hour angle is $0^{\circ}$ at solar noon. Since the earth rotate $15^{\circ}$ in every one hour, each hour away from solar noonis

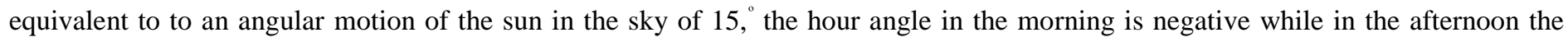
hour angle is positive. One hour of time is represented by 360/24=15 degrees of hour angle[1]. From the ratio we see that 360 is equivalent to the period of the celestial body while the 24 is equivalent to one day.

$\mathrm{HRA}=15^{\circ}(\mathrm{LST}-12)$ Delination Angle

Declanation angle is the angular distance of a celestial body from the north or to the south of the celestial equator. The equatorial plane is a plane that includes the earth's equator. If a line is drawn between the midpoint of the earth and the sun, the angle between this line and the earth's equatorial plane is called the declination.[3]. When the rays of sun are north of the equator the declination is positive and the declination is negative when they are south of the equator. At the time of winter solstice, the sun's rays are 23.5 degrees south of the earth's equator and the sun's rays are 23.5 degrees north of the earth's equator At the time of the summer solstice. The sun's declination is zero (0) at the two equinoxes since the have same value 23.5 degrees when subtracted the will give zero. The declination angle can be calculated as follows

$$
\mathrm{d}=23.45 \sin [360 / 365(284+n)] \quad \text { (degrees) }
$$

where $\mathrm{n}$ is the day of the year been selected.

\subsubsection{Clock Time and Solar Time Relation}

Computation of sun location must be induce in terms of solar time. In order to determine sun location, we are to convert local clock time into solar time. The transition between solar time and clock time demand knowledge of the position, the day of the year, and the measure to which local clocks are set [4]. Time of Greenwich meridian (zero longitude) is known as Greenwich Civil Time or worldwide Time.

Such time is explicit on an hour scale from 0 - 24. Local Civil Time is found from the delimited longitude of the percipient. On any specific meridian, Local Civil time is more advanced at the same instant than on any meridian far west and less advanced than on any meridian far east. [2] The divergence amounts to 1/900 seconds (4 minutes) of time for each degree divergence in longitude. Clocks are generally set to give the equal reading throughout the entire area been selected with a span of about 15 degrees of longitude. The time kept in each such area or zone is the Local Civil Time of a meridian near the centre or the midpoint of the area. Such time is called Standard Time. A solar day is slightly different from a 24 hours civil day due to the earth's irregularities rotation, obliquity of the earth's revolve and some of the other factors. The difference between Local Solar Time, LST and Local Civil Time, LCT is known as the equation of time.

The solar time and the clock time can be related as [2]

$\mathrm{LST}=\mathrm{CT}+(1 / 15)\left(\mathrm{L}_{\mathrm{STD}}-\mathrm{L}_{\text {loc }}\right)+\mathrm{E}-\mathrm{DT} \quad[\mathrm{hr}]$

Where, LST= Local solar time [hr]

$\mathrm{CT}=$ Clock Time $[\mathrm{hr}]$

$\mathrm{L}_{\mathrm{STD}}=$ Standard meridian of the local time zone.

$\mathrm{L}_{\text {loc }}=$ Longitude of actual location [degrees west ]

$\mathrm{E}=$ Equation of time $[\mathrm{hrs}]$.

DT= Daylight Savings Time correction, ( DT=0 if not on Daylight savings time, otherwise DT is equal to the number of hours that the time is advanced for daylight savings time, usually 1hr). Values of the Equation of Time, E, are calculated as [2] - E=0.165 sin 2B $0.126 \cos \mathrm{B}-0.025 \sin \mathrm{B}[\mathrm{hrs}]$ 
Where, $B=\frac{360(n-81)}{364}$ and $\mathrm{n}$ is the day of the year.

Thus, in order to associate local solar time with clock time, we are to reckon two correction factors apart from daylight saving time, which are longitude correction and equation of time.

Solar hour angle, h can be calculated after calculating Local Solar Time. As hour angle differs by 15 degrees per hour and as it is zero at solar noon, and negative before solar noon, the equation for the hour angle can be given by [2].

$\mathrm{h}=15(\mathrm{LST}-12) \quad[$ degrees $]$.

\subsubsection{Azimuth Angle and Altitude Angle}

The bearing of the geographical position projected horizontally from true south of the sun's radiations is called azimuth angle or azimuth (Khlaichom and Sonthipermpoon, 2007). In both methods it is an arc of the horizon (or parallel of altitude), or an angle at the zenith. It is azimuth $(\mathrm{Zn})$ if measured clockwise through $360^{\circ}$, starting at the north point on the horizon, and azimuth angle (Z) if measured either clockwise or anticlockwise through $180^{\circ}$, starting at the north point of the horizon in north latitude and the south point of the horizon in south latitude.

The solar altitude angle is defined as the angle between the horizontal plane with respects to observer and the point lines of the central ray with respect to the sun, (Khlaichom and Sonthipermpoon, 2007) as indicated in figure 4. The zenith angle is the angle in between the sun's radiations the local vertical.

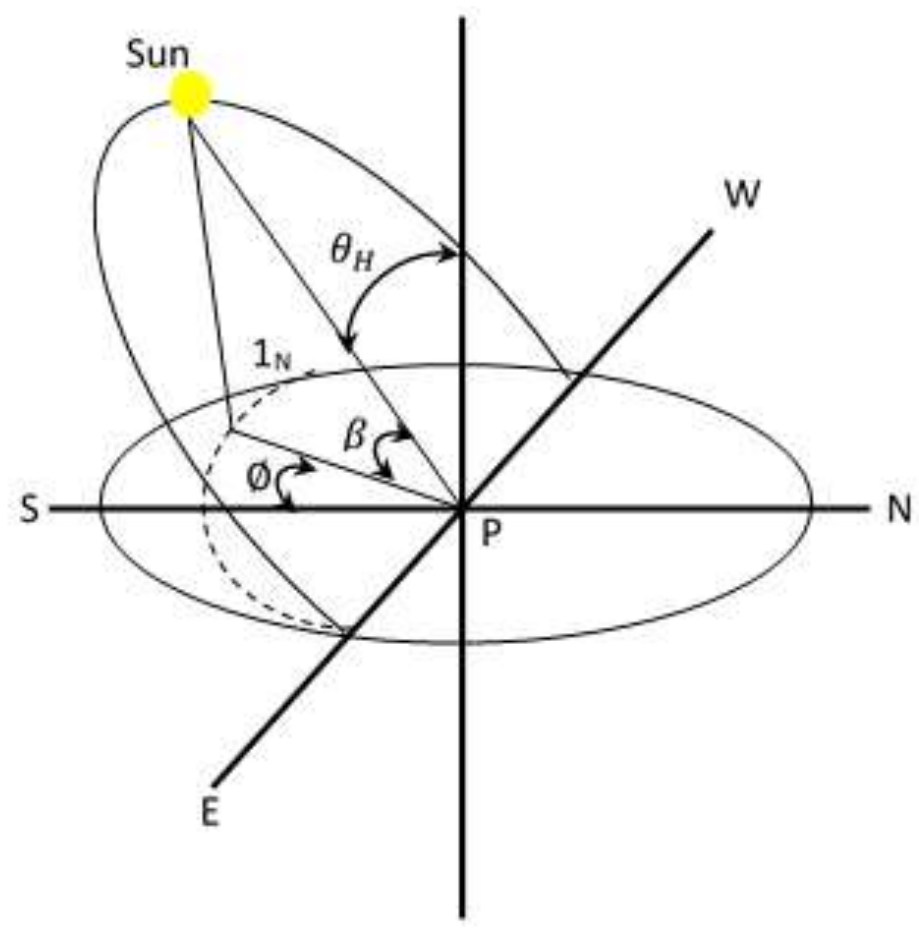

Figure 4: Sun's Azimuth, Altitude and Zenith angles ( denoted by $\Phi, \beta$ and $\theta_{H}$ )

The azimuth angle sign convention used, in the south of west direction is positive and negatively sign of south in the east direction. This outcomes always having the same sign in the sun's azimuth angle and hour angle [5].

\section{SOLAR OBSERVATION BY AZIMUTH}

Selecting amongst hour altitude method and angle method ${ }^{\text {(Sands.) }}$

Hour angle method

$$
\text { AZIMUTH }=\tan ^{-1} \frac{\sin L H A}{\sin L A T \cos L H A-\cos L A T \tan D E C}
$$


Where:

Sun local hour angle (LHA)

Sun declination (Dec)

Observer latitude (LAT)

Sun Azimuth (AZ)

\begin{tabular}{|lcc|}
\hline & To normalize $\mathbf{A Z}$, add correction \\
LHA & corr & corr \\
\hline $0-180$ & $180(+\mathrm{AZ})$ & $360(-\mathrm{AZ})$ \\
\hline $180-360$ & $0(+\mathrm{AZ})$ & $180(-\mathrm{AZ})$ \\
\hline
\end{tabular}

- Hour Altitude method

Where:

$$
Z=\cos ^{-1} \frac{\sin D E C-\sin L A T \sin h}{\cos L A T \cos h}
$$

$\mathrm{AZ}=\mathrm{Z}$ (when sun is east of the local meridian)

$A Z=360-Z$ (when sun is west of the local meridian)

$\mathrm{DEC}=$ sun declination

LAT $=$ observer latitude

$\mathrm{h}=$ vertical angle to the sun corrected for parallax and refraction.

\subsection{RESULTS}

The location of sun from celestial observation (from sky) can be stated based on its solar culmination and equations of time, solar altitude angle and solar azimuth angle. Many programs has been developed to utilized times and date as a input and finally generates the solar culmination and equations of time, the solar azimuth angle and elevation angle as output in relations to specific spatial coordinates. This kind of programs considered the seasons as well as daily variation of the sun route to track and know the sun path at a particular geographical location.

The solar elevation angle and azimuth angle for a year in Hadejia shows two maximum and minimum crest and a single trough in Figure 5, maximim crest is in between two months (April and May) elavated at an angle of $87^{\circ}$, while the minimum crest is in between three months (July, August and september) elavated at an angle $85^{\circ}$. From figure the first crest occur in the dry season while the second crest fall in raining season. Lastly the trough lied between (May and June) which are the months that separate raining and dry season in the study area. The pulsating only take placed in 6 months, while the remainig 6 months can be categorized into two; 3 months (from January to march) is a slope moving upward and the rest 3 months is a slope moving downward (from October to December), this is becaue of the present of dust and cool air (tropical continental airmass) that come from North-Eastern Sahara Africa. Figure 6 is a Changes in the solar culmination and equation of time for a year in Hadejia which pulsates between -15 to +15 after computing the values.

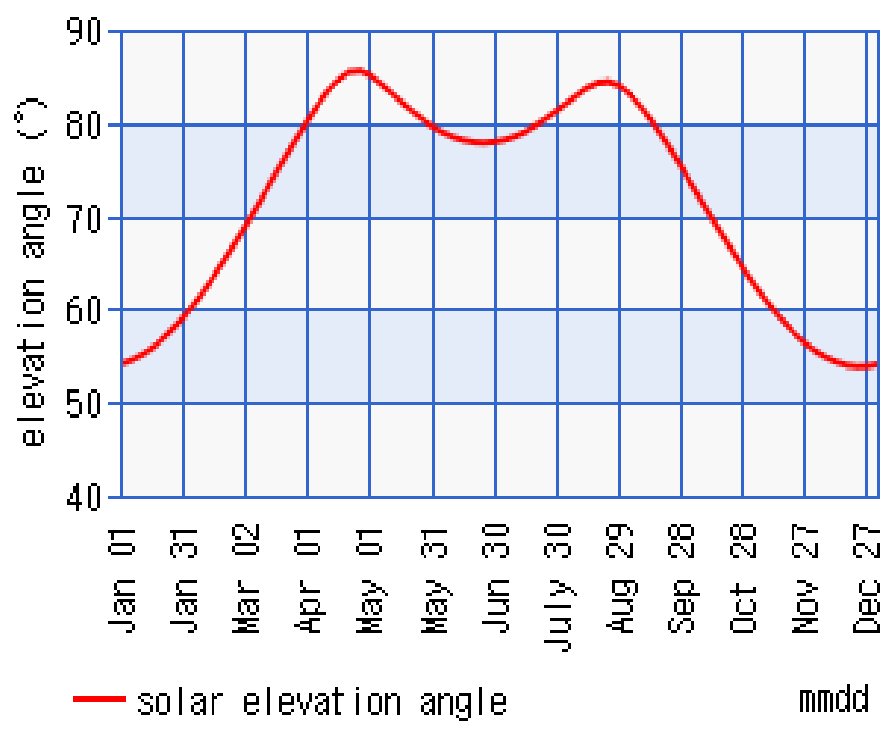


Figure 5. Solar elevation angle and Azimuth angle for a year in Hadejia (2017)

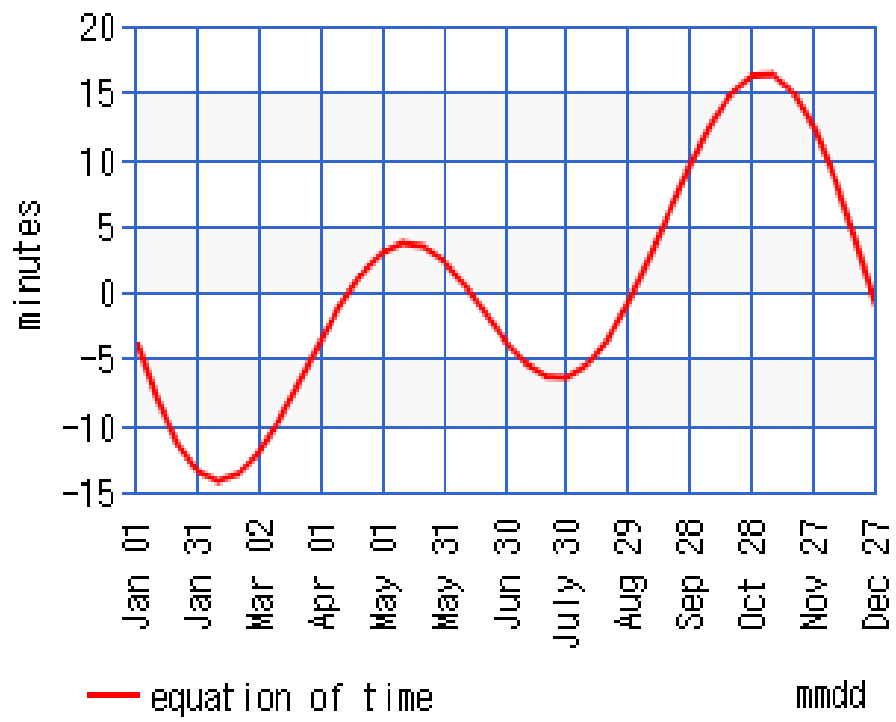

Figure 6. Changes in the solar culmination and equation of time for a year in Hadejia (2017)

The results in appendix 1 and 2 indicates that there is a variation of the sun elevation angle at different months and this was depends on date and time of the year. When spatial coordinate in terms of latitude and longitude of specific points of the earths is known, the solar path/position with respects to solar azimuth and solar elevation angle as well as solar culmination can be tracked. Our finding indicated maximum azimuth angle and equation of time on November 07, while minimum culmination was also observed within the months of November.

\subsection{CONCLUSION}

Due to advancement and creations of new innovation in the field of technology. Solar energy is the effective alternative energy source globally. Understanding the exact position of the sun for certain geographical area has a significant influence for the utilization of solar energy of that area. The maximum utilization of global solar energy can be properly achieved by computer programs, and calculation of solar azimuth, elevation angle, solar path, solar culmination and equation of times for any specific geographic location. Furthermore, understanding solar energy relative variables will be an important information to obtain. Measures and decisions for harnessing solar energy in any spatial locations and can be used to determine proper time to stored sun energy using solar panel technology within different seasons for any geographic area [7].

\section{Authors Contributions}

M. Abdurrahman and I. G. Shitu reviewed the literature; Z. Dahiru and A. M. Idris extract the data and make it meaningful information; A. A. Isah produced all figures; while interpretation of results done by Y. A. Yusuf. While J. Gambo designed the methodology, restructured the article, and supervised the entire work.

\section{Conflict of Interests.}

The author(s) have not declared any conflict of interests.

\section{Acknowledgements.}

I would like to thank Binyaminu Usman Polytechnic, Hadejia for providing conducive environment with free internet access during the research work.

\section{REFERENCES}

1. V. Panwar and T. Kaur, "Overview of Renewable Energy Resources of India," Int. J. Adv. Res. Electr. Electron. Instrum. Eng., vol. Vol. 3, no. Issue 2, pp. 7118-7125, 2014. 
International Journal of Advances in Scientific Research and Engineering (ijasre), Vol 5 (9), September-2019

2. A. A. Kumar, “A STUDY ON RENEWABLE ENERGY RESOURCES IN INDIA,” in 2010 International Conference on Environmental Engineering and Applications ( ICEEA 2010 ), 2010, no. Iceea, pp. 49-53.

3. D. A. Pio, "Longitude from Moon Culminations," R. Astron. Soc. , Provid. by NASA Astrophys. Data Syst., no. May, 1899.

4. P. Khlaichom and K. Sonthipermpoon, "Optimization of Solar Tracking System,” in 3rd Thailand Energy Network Conference Baiyoke Sky Hotel Bangkok, 2007, pp. 1-10.

5. S. Ray, "Calculation of Sun Position and Tracking the Path of Sun for a Particular Geographical Location," vol. 2, no. 9, pp. 81-84, 2012.

6. J. Sands, “AZIMUTH DETERMINATION BY CELESTIAL OBSERVATION County of San Diego.”

7. Q. Zhang, H. Yu, Q. Zhang, Z. Zhang, C. Shao, and D. Yang, “A Solar Automatic Tracking System that Generates Power for Lighting Greenhouses," no. ii, pp. 7367-7380, 2015.

\section{Appendix}

Appendix 1. Solar elevation angle for a year 2017 (Hadejia Town).

\begin{tabular}{lrrrrr}
\hline \multicolumn{1}{c}{ Date } & Elevation angle & Azimuth angle & Date & Elevation angle & Azimuth angle \\
\hline 1-Jan & 54.13 & 170.75 & 5-Jul & 78.18 & 28.65 \\
6-Jan & 54.55 & 169.7 & 10-Jul & 78.57 & 30.87 \\
11-Jan & 55.15 & 168.65 & 15-Jul & 79.09 & 33.55 \\
16-Jan & 55.92 & 167.58 & 20-Jul & 79.74 & 36.81 \\
21-Jan & 56.86 & 166.51 & 25-Jul & 80.49 & 40.85 \\
26-Jan & 57.95 & 165.43 & 30-Jul & 81.32 & 45.94 \\
31-Jan & 59.18 & 164.35 & 4-Aug & 82.19 & 52.5 \\
5-Feb & 60.56 & 163.27 & 9-Aug & 83.05 & 61.17 \\
10-Feb & 62.05 & 162.19 & 14-Aug & 83.79 & 72.71 \\
15-Feb & 63.65 & 161.08 & 19-Aug & 84.29 & 87.58 \\
20-Feb & 65.35 & 159.94 & 24-Aug & 84.38 & 104.9 \\
25-Feb & 67.12 & 158.73 & 29-Aug & 83.97 & 122.09
\end{tabular}


International Journal of Advances in Scientific Research and Engineering (ijasre), Vol 5 (9), September-2019

\begin{tabular}{lrrlrr}
\hline 2-Mar & 68.96 & 157.44 & 3-Sep & 83.09 & 136.63 \\
7-Mar & 70.85 & 156 & 8-Sep & 81.85 & 147.76 \\
12-Mar & 72.77 & 154.36 & 13-Sep & 80.37 & 155.96 \\
17-Mar & 152.4 & 18-Sep & 78.72 & 161.98 \\
22-Mar & 76.69 & 149.96 & 23-Sep & 76.96 & 166.45 \\
27-Mar & 76.61 & 146.78 & 28-Sep & 75.14 & 169.81 \\
1-Apr & 78.49 & 142.47 & 3-Oct & 73.28 & 172.35 \\
6-Apr & 80.3 & 136.36 & 8-Oct & 71.42 & 174.29 \\
11-Apr & 82 & 127.35 & 13-Oct & 69.57 & 175.73 \\
16-Apr & 83.52 & 113.91 & 18-Oct & 67.75 & 176.78 \\
21-Apr & 85.16 & 23-Oct & 65.98 & 177.51 \\
26-Apr & 85.43 & 73.84 & 28-Oct & 64.28 & 177.97 \\
1-May & 55.6 & 2-Nov & 62.66 & 178.21 \\
6-May & 85.55 & 42.88 & 7-Nov & 61.15 & 178.25 \\
11-May & 85.06 & 34.66 & 12-Nov & 59.74 & 178.12 \\
16-May & 84.22 & 29.44 & 17-Nov & 58.45 & 177.82 \\
21-May & 83.23 & 26.17 & 22-Nov & 57.31 & 177.39 \\
26-May & 82.22 & 24.19 & 27-Nov & 56.31 & 176.85 \\
31-May & 81.25 & 23.11 & 2-Dec & 55.47 & 176.2 \\
5-Jun & 80.37 & 22.68 & 7-Dec & 54.8 & 175.46 \\
10-Jun & 79.6 & 22.75 & 12-Dec & 54.3 & 174.64 \\
15-Jun & 78.96 & 23.24 & 17-Dec & 53.98 & 173.75 \\
20-Jun & 78.46 & 24.1 & 22-Dec & 53.84 & 172.8 \\
25-Jun & 78.11 & 25.29 & 27-Dec & 53.89 & 171.82 \\
30-Jun & 77.9 & 26.8 & 1-Jan & 54.12 & 170.8 \\
\hline
\end{tabular}

Appendix 2. Solar culmination and equation of time for a year 2017 (Hadejia town)

\begin{tabular}{lll}
\hline Date & Equation of time(m) & Culmination \\
\hline 1-Jan & -3.659 & $12: 23: 30$ \\
11-Jan & -7.996 & $12: 27: 50$ \\
21-Jan & -11.343 & $12: 31: 11$ \\
31-Jan & -13.453 & $12: 33: 17$ \\
10-Feb & -14.198 & $12: 34: 02$ \\
20-Feb & -13.666 & $12: 33: 30$ \\
2-Mar & -12.076 & $12: 31: 55$ \\
12-Mar & -9.673 & $12: 29: 31$ \\
22-Mar & -6.794 & $12: 26: 38$ \\
1-Apr & -3.797 & $12: 23: 38$ \\
11-Apr & -0.975 & $12: 20: 49$ \\
21-Apr & 1.359 & $12: 18: 29$ \\
1-May & 2.944 & $12: 16: 54$ \\
\hline
\end{tabular}


International Journal of Advances in Scientific Research and Engineering (ijasre), Vol 5 (9), September-2019

\begin{tabular}{lll}
\hline 11-May & 3.659 & $12: 16: 11$ \\
21-May & 3.428 & $12: 16: 25$ \\
31-May & 2.308 & $12: 17: 32$ \\
10-Jun & 0.543 & $12: 19: 18$ \\
20-Jun & -1.581 & $12: 21: 25$ \\
30-Jun & -3.696 & $12: 23: 32$ \\
10-Jul & -5.383 & $12: 25: 13$ \\
20-Jul & -6.358 & $12: 26: 12$ \\
30-Jul & -6.421 & $12: 26: 16$ \\
9-Aug & -5.46 & $12: 25: 18$ \\
19-Aug & -3.555 & $12: 23: 24$ \\
29-Aug & -0.863 & $12: 20: 42$ \\
8-Sep & 2.412 & $12: 17: 26$ \\
18-Sep & 5.949 & $12: 13: 53$ \\
28-Sep & 9.422 & $12: 10: 25$ \\
8-Oct & 12.524 & $12: 07: 19$ \\
18-Oct & 14.891 & $12: 04: 57$ \\
28-Oct & 16.226 & $12: 03: 37$ \\
7-Nov & 16.323 & $12: 03: 31$ \\
17-Nov & 15.016 & $12: 04: 49$ \\
27-Nov & 12.329 & $12: 07: 31$ \\
7-Dec & 8.488 & $12: 11: 21$ \\
17-Dec & 3.825 & $12: 16: 01$ \\
27-Dec & -1.136 & $12: 20: 58$ \\
\hline & & \\
\hline & &
\end{tabular}

